\title{
Association Between Urologist Characteristics and Radiation Oncologist Consultation for Patients With Locoregional Prostate Cancer
}

\author{
Ruben G.W. Quek, PhD; ; Kevin C. Ward, PhD, MPH' ; Viraj A. Master, MD, PhD c,d Chun Chieh Lin, PhD, MBA; \\ Kenneth M. Portier, $\mathrm{PhD}^{\mathrm{f,g}}$; Katherine S. Virgo, PhD, MBA ${ }^{\mathrm{a}}$; and Joseph Lipscomb, PhD,
}

\begin{abstract}
Background: Physicians managing patients with prostate cancer play a critical role in subsequent specialist consultations and initial treatment choice, especially in cases for which no consensus exists regarding optimal treatment strategy. The NCCN Guidelines for Prostate Cancer recommend radiation as a therapy option for patients with locoregional prostate cancer. Purpose: The authors examined the association of urologist characteristics with the likelihood that patients would consult radiation oncologists. Methods: A retrospective cohort of 39,934 patients aged 66 years or older who were diagnosed with locoregional prostate cancer between 2004 and 2007 , and the 2405 urologists who performed the patient diagnostic biopsies were constructed using the SEER-Medicare linked database and the American Medical Association Physician Masterfile. Logistic multilevel regression analysis was used to evaluate the influence of urologists' characteristics on radiation oncologist consultation within 9 months of locoregional prostate cancer diagnosis. Results: Overall, 24,549 (61.5\%) patients consulted a radiation oncologist. After adjusting for patient and urologist characteristics, patients diagnosed by urologists in noninstitutional settings (eg, physician office) were significantly more likely to consult a radiation oncologist (odds ratio [OR], $1.40 ; 95 \%$ $\mathrm{Cl}, 1.17-1.67 ; P=.0002)$ compared with those diagnosed by urologists in institutional settings with a major medical school affiliation. In addition, patients diagnosed by urologists older than 57 years were significantly more likely to consult a radiation oncologist (OR, $1.21 ; 95 \%$ Cl, 1.07-1.38, P=.003). (J Natl Compr Canc Netw 2015;13:303-309)
\end{abstract}

\section{Background}

With insufficient high-quality evidence to identify an optimal prostate cancer treatment modality, ${ }^{1}$ preferences of individual physicians can significantly affect management decisions of this disease. The NCCN Clinical Practice Guidelines in Oncology (NCCN Guidelines) for Prostate Cancer $^{2}$ include radiation therapy as a treatment option for men with locoregional prostate cancer (to view the most recent version of these guidelines, visit NCCN.org). Many patients seek information and recommendations from urologists and radiation oncolo-

From the a Department of Health Policy and Management, bDepartment of Epidemiology, 'Winship Cancer Institute, and dDepartment of Urology, Emory University; ' Surveillance and Health Services Research Program, and Statistics and Evaluation Center, Intramural Research Department, American Cancer Society; and ${ }^{D}$ Department of Biostatistics and Bioinformatics, Emory University, Atlanta, Georgia.

Submitted April 21, 2014; accepted for publication July 18, 2014. The authors have disclosed that they have no financial interests, arrangements, affiliations, or commercial interests with the manufacturers of any products discussed in this article or their competitors. This study was supported by the American Cancer Society, Intramural Research Department, Atlanta, Georgia. Correspondence: Ruben G.W. Quek, PhD, Department of Health Policy and Management, Emory University, 1518 Clifton Road NE, MS: 1518002-6AA, Atlanta GA 30322. E-mail: ruben.quek@alum.emory.edu gists, ${ }^{3}$ the 2 most common specialists providing prostate cancer care. ${ }^{4}$ Urologists generally act as both diagnosticians (eg, diagnosing prostate cancer after performing diagnostic core needle biopsy) and proceduralists (eg, performing radical prostatectomy). In contrast, radiation oncologists usually act solely as proceduralists (eg, administering radiation therapy) during prostate cancer treatment. In the United States, urologists perform biopsies for patients with suspected prostate cancer and are generally the first physicians to discuss further diagnostic, treatment, and referral options.

A study comparing recommendations by urologists and radiation oncologists found that physicians overwhelmingly recommended therapy that they themselves deliver. ${ }^{5}$ Likewise, studies have reported a strong correlation between specialty seen and initial treatment received by patients with prostate cancer. ${ }^{3,4,6}$ Physicians play a major role in influencing patients' treatment decisions. ${ }^{7,8} \mathrm{Mul}$ tiple studies have indicated that physician characteristics are important determinants of referral patterns. ${ }^{9-13}$

This study examined urologists' characteristics as determinants of radiation oncologist consultation for patients with locoregional prostate cancer. 
Quek et al

\section{Methods}

\section{Data Sources}

Incident locoregional prostate cancer cases for 2004 through 2007 were selected from the SEER-Medicare database that links cancer registry information in selected US geographic areas with claims for covered health care services of Medicare beneficiaries (Figure 1). The SEER program represents $26 \%$ of the US population, whereas Medicare covers health services for $97 \%$ of people aged 65 years and older. ${ }^{14,15}$ Approximately $94 \%$ of SEER patients aged 65 years or older have been successfully linked with their Medicare claims. ${ }^{14,15}$ Geographic areas selected for inclusion in the SEER program are based on their ability to operate and maintain a high-quality, population-based cancer reporting system and for their

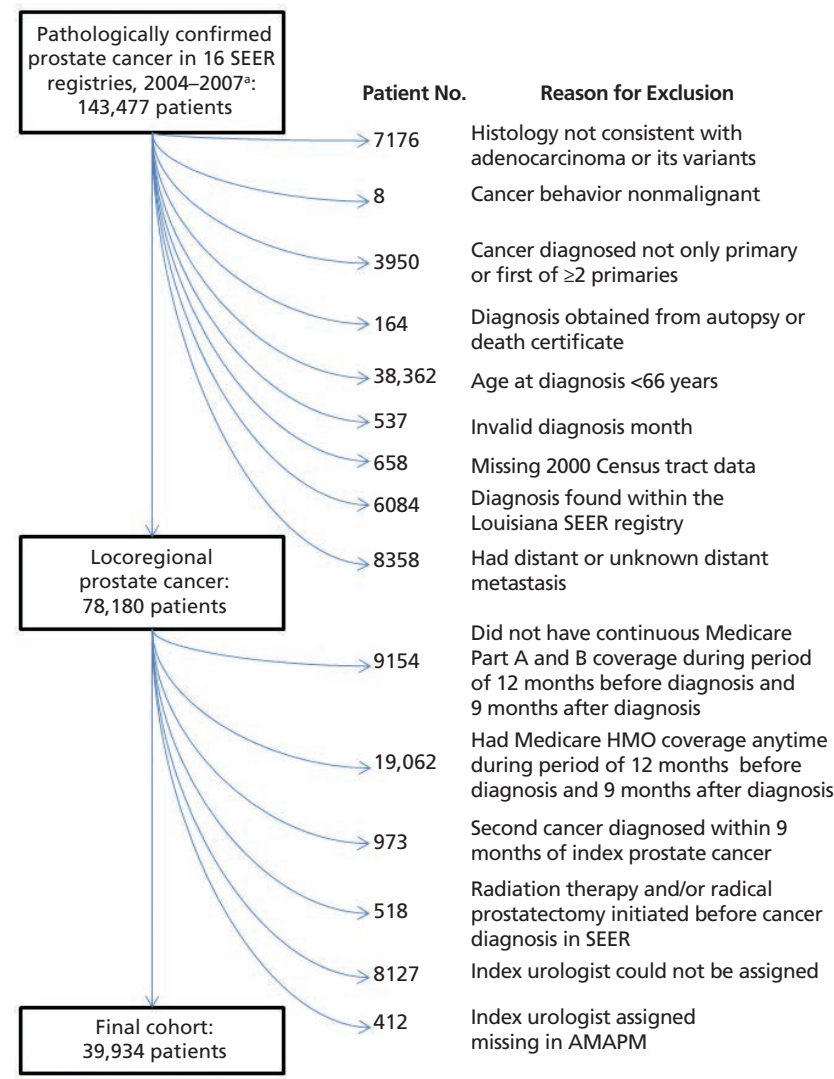

Figure 1 Definition of study cohort of 39,934 men with locoregional prostate cancer.

Abbreviations: AMAPM, American Medical Association Physician Masterfile; $\mathrm{HMO}$, health maintenance organization.

aExact prostate-specific antigen levels at time of diagnosis were recorded in SEER from 2004, and up until 2007, Medicare files used Unique Physician Identification Numbers that are required to link with the AMAPM. epidemiologically significant population subgroups. ${ }^{16}$ Louisiana SEER registry data were removed from this study because of missing information after Hurricane Katrina in 2005. Exact prostate-specific antigen (PSA) levels at time of diagnosis were not recorded in SEER until 2004. Until 2007, Medicare files used Unique Physician Identification Numbers that are required to link with the American Medical Association Physician Masterfile (AMAPM).

Characteristics of physicians who treated SEERMedicare patients were obtained from the AMAPM. This file contains physician information collected from multiple sources, including medical schools, state licensing boards, and the American Board of Medical Specialties (ABMS). ${ }^{17}$

Guidelines, published annually by NCCN since 1996 and throughout the study period, have consistently recommended radiation as a possible initial treatment option for locoregional prostate cancer (any $\mathrm{T}$, any $\mathrm{N}, \mathrm{MO}){ }^{18-24}$

An analytical cohort of patients with an index urologist was created using registry-claims linked data. Urologists perform core needle biopsies (Healthcare Common Procedure Coding System code 55700) to diagnose prostate cancer. ${ }^{25,26}$ The urologist who performed the biopsy on the day closest to the patients' diagnosis date in SEER was assigned as the index urologist. Patients diagnosed with prostate cancer without undergoing biopsy, received their biopsy from a non-urologist, or had multiple biopsies performed by different urologists on the day closest to the patients' diagnosis date were removed. These exclusions create a more homogenous population in terms of treatment selection.

Institutional Review Board approval was obtained from Emory University and Morehouse School of Medicine.

\section{Patient Characteristics}

Sociodemographic and clinical characteristics of the analytic cohort were extracted from SEER data (see supplemental eTable 1, available with this article at JNCCN.org). For tumor grade, low corresponds to Gleason grade 2 through 4; intermediate to Gleason grade 5 through 6 , and high to Gleason grade 7 through $10 .{ }^{27}$ Education and income levels were based on US Census tract data from 2000; the categories chosen were prespecified to ensure a reasonable distribution, with cutoffs approximately corresponding to quartiles. The prevalence of comorbid disease in the 
study cohort was calculated using a modified Charlson comorbidity index derived from Medicare Part A and Part B claims. ${ }^{28}$

\section{Urologist Characteristics}

Urologists were identified by using either the Health Care Financing Administration (HCFA) specialty codes in Medicare claims, the physician specialty information from the AMAPM, or the urology board certification identified through the ABMS information within the AMAPM. Other urologist characteristics extracted from the AMAPM can be found in supplemental eTable 1). Urologists' patient volume was defined as the number of unique patients with prostate cancer that each urologist saw during the study period. Categories used for urologists' patient volume, age, and years after medical school graduation were prespecified to ensure cutoffs approximating quartiles.

\section{Physician Medical School Affiliation}

Urologists' medical school affiliation was derived from the SEER-Medicare Hospital (HOSP) file. ${ }^{29}$ Specifically, if the Medicare biopsy claim recorded in the institutional outpatient standard analytical file (OUTSAF) was submitted from a hospital with a major or without a medical school affiliation (as defined within the HOSP file), the associated index urologist was categorized as having a major or no medical school affiliation, respectively. Index urologists were categorized as having mixed medical school affiliations if the OUTSAF biopsy claims were from hospitals with limited or graduate medical school affiliations. ${ }^{30}$

Biopsy claims found within the National Claims History $(\mathrm{NCH})$ file (consisting of mostly noninstitutional physician/supplier claims) did not have the associated provider (eg, hospital) identifier required to retrieve medical school affiliation (found within HOSP) for the index urologist. These $\mathrm{NCH}$ claims were assigned the provider identifier associated with the institutional inpatient Medicare Provider Analysis and Review (MEDPAR) claims if (1) the patient associated with both types of claims matched, (2) the NCH place of service was institutional, ${ }^{31}$ and (3) the NCH claims dates fell between the MEDPAR admission and discharge dates.

Subsequently, remaining $\mathrm{NCH}$ biopsy claims without assigned provider identifiers from MEDPAR claims were assigned provider identifiers from
OUTSAF claims if (1) the patient and urologist associated with both claim types matched, (2) the $\mathrm{NCH}$ place of service was institutional, ${ }^{31}$ and (3) the $\mathrm{NCH}$ claims dates were between the OUTSAF claims dates. Urologists whose biopsy claims were only found in the $\mathrm{NCH}$ file and whose claims could not be assigned provider identifiers from OUTSAF or MEDPAR claims were categorized as having a noninstitutional affiliation.

\section{Measurement of Outcomes}

Whether the patient had a radiation oncologist consultation after being diagnosed with locoregional prostate cancer was the primary dichotomous outcome. Radiation oncologists were identified using either HCFA specialty codes, AMAPM's physician specialty information, or ABMS radiation oncology board certification information. Patients were categorized as having radiation oncologist consultations if at least one radiation oncologist-associated Medicare claim was identified within 9 months after locoregional prostate cancer was diagnosed. A 9-month interval was selected to ensure sufficient time for multidisciplinary consultations with specialists before treatment selection ${ }^{4}$ and to minimize the possibility of significant cancer progression. A total of 568 patients who underwent prostatectomy before radiation oncologist consultation were excluded in the outcome measurement. As part of a sensitivity analysis to examine the impact of these consultations as potentially part of adjuvant radiation therapy, these patients were included in the outcome measurement but the results were not substantially changed (unpublished data, 2014).

\section{Statistical Analyses}

Differences in the proportion of patients consulting radiation oncologists across index urologists and patient characteristics were evaluated using chi-square tests. The effect of patient and urologist characteristics on the likelihood of a subsequent radiation oncologist consultation was assessed with logistic hierarchical generalized linear mixed models ${ }^{32}$ (GLMM) and estimated using restricted pseudo-likelihood methodology. ${ }^{32-34}$ The use of hierarchical GLMM accounted for possible clustering of subsequent radiation oncologist consultation among patients who had the same index urologist for diagnostic biopsy. ${ }^{29,35-37}$ The unit of analysis was the patient. The clustering variable was the index urologist associated with each 
Quek et al

patient. Univariate and adjusted multivariate odds ratios (ORs) and 95\% CIs for the radiation oncologist consultation were calculated for each patient and urologist characteristic (supplemental eTable 2). Variables used in the adjusted model were selected a priori and based on previous studies that investigated the influence of patient and physician characteristics on clinical referral patterns. ${ }^{12,38}$

All statistical testing was 2-sided, performed at $5 \%$ significance level, and used SAS version 9.3 (SAS Institute, Cary, NC).

\section{Results}

The SEER-Medicare database contained 39,934 men diagnosed with incident locoregional prostate cancer from 2004 to 2007 who met study eligibility criteria. A total of 2405 urologists performed diagnostic biopsies on these patients, and were predominantly male $(96.8 \%)$, board certified $(93.4 \%)$, had patient volumes across the study period of fewer than 37 $(60.5 \%)$, were trained in the United States $(84.4 \%)$, and had an MD (97.6\%) as opposed to a DO degree (supplemental eTable 3).

Overall, 24,549 (61.5\%) patients consulted a radiation oncologist within 9 months after diagnosis (supplemental eTable 1). Radiation oncologist consultations were less common among patients who were aged 80 years or older; of Hispanic ethnicity; unmarried; residing in SEER areas covering Iowa, New Mexico, or Utah; and residing in census tracts with lower educational and median incomes levels. Consultations were also less common among patients with higher levels of comorbidities, tumor stages higher than T1, PSA levels greater than 20 $\mathrm{ng} / \mathrm{mL}$, low tumor grade, and/or positive regional lymph nodes. Index urologists treating patients who consulted radiation oncologists were more likely to be older than 57 years, have a patient volume of fewer than 37 , be trained in the United States, and/or have a mixed medical school affiliation.

Using hierarchical GLMM, factors associated with patients' subsequent radiation oncologist consultation after diagnosis were investigated, while controlling for multiple patients being diagnosed by the same urologist (supplemental eTable2). Unadjusted univariate ORs showed that lower propensities to consult radiation oncologists are associated with patients who were aged 80 years or older; of Hispanic ethnicity compared with white; were unmarried; residing in California, Detroit, Iowa, Kentucky, New Mexico, Seattle, or Utah as opposed to Georgia; and residing in census tracts with lower educational and/ or median income levels. A significantly smaller association with radiation oncologist consultation was also observed for patients with higher levels of comorbidities (ie, comorbidity index $\geq 3$ vs 0 ), clinical stage T2-T4 versus T1, regional lymph node metastasis stage N1 versus N0, low versus high tumor grade, and higher PSA levels. The index urologists for patients who subsequently consulted radiation oncologists were significantly more likely to have noninstitutional affiliations (OR, 1.21; 95\% CI, $1.02-1.43 ; P=.03)$.

After the multivariate adjustment for patient and urologist characteristics, patients whose index urologists had noninstitutional affiliations (OR, $1.40 ; 95 \% \mathrm{CI}, 1.17-1.67 ; P=.0002$ ) as opposed to major medical school affiliations were significantly more likely to have a subsequent radiation oncologist consultation. In addition, patients who subsequently consulted radiation oncologists were also significantly more likely to be diagnosed by index urologists older than 57 years (OR, 1.21; 95\% CI, $1.07-1.38 ; P=.003$ ) and/or significantly less likely to be diagnosed by index urologists with patient volumes between 37 and 54 (OR, 0.88; 95\% CI, 0.78 $1.00 ; P=.049$ ) as opposed to fewer than 37 . Patient characteristics that remained significantly associated with lower odds of radiation oncologists consultation included age of 80 years or older; Hispanic ethnicity versus white; SEER region of residence in California, Iowa, or Utah as opposed to Georgia; residence in census tracts with lower educational levels; clinical stage T2-T4 versus T1; lower tumor grade; and PSA levels greater than $20.0 \mathrm{ng} / \mathrm{mL}$ compared with 0.1 to $9.9 \mathrm{ng} / \mathrm{mL}$.

\section{Discussion}

To our knowledge, this is the first study to investigate the association of urologists' characteristics on the likelihood of subsequent radiation oncologist consultation by men diagnosed with locoregional prostate cancer. The index urologists' age, patient volume, and noninstitutional practice affiliation exerted a significant influence on patients' subsequent radiation oncologist consultations. Similar radiation 
oncologist consultation patterns were found among patients diagnosed by institutional-affiliated urologists regardless of medical school affiliation level (major/mixed). Other significant associations found between patient-related sociodemographic and clinical factors and radiation oncologist consultations complement prior research. ${ }^{4}$

Significant associations with urologist age may be a result of younger urologists being keener to act as proceduralists and not actively referring their patients to radiation oncologists. In addition, older urologists may not feel the need to perform multiple procedures, and prefer the added value of a radiation oncologist consultation.

Physician practice settings are known to be associated with variation in primary treatment of prostate cancer ${ }^{39}$; inherent differences may exist between physicians practicing within major medical schools and those in noninstitutional settings that may explain observed variations. One possible reason major medical school-affiliated urologists refer less often may be related to the teaching nature of their institutions. Urologists affiliated with major medical schools may potentially want to reserve patients for their residents and fellows to perform surgery.

Given the rising prevalence of expectant management approaches during this study period, ${ }^{39}$ many of the patients who did not consult a radiation oncologist may have opted for active surveillance or watchful waiting. Current NCCN Guidelines ${ }^{2,40,41}$ recommend active surveillance for low-risk patients with an expected survival of less than 10 years and very-low-risk patients with an expected survival of less than 20 years (to view the most recent version of these guidelines, visit NCCN.org). However, during this study period, NCCN Guidelines ${ }^{18-24}$ allowed for expectant management or radiation therapy as possible treatment options for low-risk patients with an expected survival of less than 10 years. A significant proportion $(27 \%-69 \%)$ of the study's patients aged 75 years or older (with an expected survival $\approx<10$ years $)^{42}$ had a radiation oncologist consultation. Based on current NCCN Guidelines, ${ }^{2}$ future research should investigate whether radiation oncologists should discuss treatment options with all of these patients. In addition, uncertainty surrounds the threshold for reclassifying prostate cancer from low risk to higher risk, which would trigger a physician recommendation for active treatment. ${ }^{40}$ Ongo- ing randomized clinical trials ${ }^{43}$ will further inform this important management decision and the need for multiple specialty consultations.

Physicians working for academic health providers are more commonly remunerated through a salaryonly payment mechanism rather than a fee-for-service (FFS) model. ${ }^{44}$ Previous research has shown that different payment mechanisms influence clinical decision-making ${ }^{45}$ and physician behavior is significantly different under salaried versus FFS reimbursement models. A previous study concluded that, regarding inappropriate androgen deprivation therapy use, financial incentives might have played a lesser role for major medical school-affiliated urologists, because they were more likely to be salaried. ${ }^{36}$ In another recent study, urologists employed by NCCN Member Institutions (generally major medical school-affiliated institutions) were unlikely to derive financial benefits from recommending specific treatments such as intensity-modulated radiation therapy (IMRT). ${ }^{26}$

SEER-Medicare data limitations preclude direct ascertainment of individual physicians' payment mechanisms (ie, salaried vs nonsalaried) and selfreferral confirmation (ie, that the radiation oncologist and index urologist worked within the same practice; and that the urologist had a financial interest in the referral). Nonetheless, a 2012 report by the US Government Accountability Office (GAO) that investigated advanced imaging self-referral concerns noted that "financial incentive for providers to selfrefer is most direct when the service is performed in a physician office." ${ }^{46}$ In our study, as expected, greater than $90 \%$ of patients diagnosed by noninstitutionalaffiliated urologists received biopsies in physician office settings. The GAO report also found that between 2004 and 2010, the greatest increase in CT self-referral rates occurred among urology and radiation oncology providers. ${ }^{46}$ Our findings may shed further light on the determinants of radiation oncologist consultations before IMRT self-referrals that were reported in another $2013 \mathrm{GAO}$ report. ${ }^{47}$

We acknowledge other important study limitations when using the SEER-Medicare database. ${ }^{14,15,17}$ Multiple physician characteristics (eg, intrinsic motivation, professionalism, altruism) not measured in this study may influence practice patterns or response to financial incentives. ${ }^{48-52}$ Medicare claims-based categorization of medical school affiliation may be influenced by other patients seen (eg, younger pa- 
tients, those with private insurance, and/or receiving care in health maintenance organizations). Therefore, our study observations may not be representative of the physicians' entire practice. Nonetheless, $79 \%$ of men with incident prostate cancer are aged 65 years or older, ${ }^{53}$ and in 2010, $76 \%$ of Medicare beneficiaries were covered under traditional FFS. ${ }^{54}$ Medicare claims-based categorization of physicians' medical school affiliation has also been used in previous literature. ${ }^{29,30,36,37}$

Whether a patient sees a radiation oncologist is likely influenced by many other factors. Individual patient selection biases not assessed may have led to variability in observations. Whether the present observations reflect urologists' referral decisions or patients' individual choices is unclear. Nonetheless, previous studies ${ }^{55,56}$ suggest that patient preference is unlikely to entirely explain the observed radiation oncologist consultation patterns. Further research is necessary to confirm whether subsequent radiation oncologist consultations reflect index urologist referral behavior, patient response, or urologist-patient interactions. Future studies should also examine subsequent urologist consultation after diagnosis and the association of physicians' (both urologist and radiation oncologist) characteristics on the eventual treatment received by patients with prostate cancer.

Without a gold standard for prostate cancer treatment, urologists' recommendations and referrals can be crucial in determining eventual treatment. Inherent differences in specialty-related treatment recommendations ${ }^{5,6}$ underscore the importance of obtaining second opinions from different types of specialists before selecting a specific treatment modality. Nevertheless, variation observed in this study should ideally be from the collective preferences and consents of well-informed patients and patient-centered clinical judgment of their physicians.

\section{Acknowledgments}

The authors acknowledge the efforts of the Applied Research Program, Division of Cancer Control and Population Sciences, NCI; the Office of Research, Development and Information, Centers for Medicare \& Medicaid Services; Information Management Services, Inc; and the SEER Program tumor registries in the creation of the SEER-Medicare database.

\section{References}

1. Wilt TJ, MacDonald R, Rutks I, et al. Systematic review: comparative effectiveness and harms of treatments for clinically localized prostate cancer. Ann Intern Med 2008;148:435-448.

2. Mohler JL, Armstrong AJ, Bahnson RR, et al. NCCN Clinical Practice Guidelines in Oncology: Prostate Cancer. Version 1, 2015. Available at: NCCN.org. Accessed February 6, 2015.

3. McNaughton Collins M, Barry MJ, Zietman A, et al. United States radiation oncologists' and urologists' opinions about screening and treatment of prostate cancer vary by region. Urology 2002;60:628-633.

4. Jang TL, Bekelman JE, Liu YH, et al. Physician visits prior to treatment for clinically localized prostate cancer. Arch Intern Med 2010;170:440-450.

5. Fowler FJ Jr, Collins MM, Albertsen PC, et al. Comparison of recommendations by urologists and radiation oncologists for treatment of clinically localized prostate cancer. JAMA 2000;283:3217-3222.

6. Moore MJ, Osullivan B, Tannock IF. How expert physicians would wish to be treated if they had genitourinary cancer. J Clin Oncol 1988;6:17361745 .

7. Miles BJ, Giesler B, Kattan MW. Recall and attitudes in patients with prostate cancer. Urology 1999;53:169-174.

8. Hall JD, Boyd JC, Lippert MC, et al. Why patients choose prostatectomy or brachytherapy for localized prostate cancer: results of a descriptive survey. Urology 2003;61:402-407.

9. Franks P, Clancy CM. Referrals of adult patients from primary care: demographic disparities and their relationship to HMO insurance. J Fam Pract 1997;45:47-53.

10. Earle CC, Neumann PJ, Gelber RD, et al. Impact of referral patterns on the use of chemotherapy for lung cancer. J Clin Oncol 2002;20:1786-1792.

11. Steyerberg EW, Neville B, Weeks JC, Earle CC. Referral patterns, treatment choices, and outcomes in locoregional esophageal cancer: a population based analysis of elderly patients. J Clin Oncol 2007;25:2389-2396.

12. Luo RL, Giordano SH, Zhang DD, et al. The role of the surgeon in whether patients with lymph node-positive colon cancer see a medical oncologist. Cancer 2007;109:975-982.

13. Oliveria SA, Yood MU, Campbell UB, et al. Treatment and referral patterns for colorectal cancer. Med Care 2004;42:901-906.

14. Potosky AL, Riley GF, Lubitz JD, et al. Potential for cancer related health services research using a linked Medicare-tumor registry database. Med Care 1993;31:732-748.

15. Warren JL, Klabunde CN, Schrag D, et al. Overview of the SEER Medicare data: content, research applications, and generalizability to the United States elderly population. Med Care 2002;40(8 Suppl):IV 3-18.

16. SEER registries: population characteristics. SEER Web site. Available at: http://seer.cancer.gov/registries/characteristics.html. Accessed February 6 2015.

17. Baldwin LM, Adamache W, Klabunde CN, et al. Linking physician characteristics and Medicare claims data: issues in data availability, quality, and measurement. Med Care 2002;40(8 Suppl):IV-82-95.

18. Baker LH, Hanks G, Gershenson D, et al. NCCN prostate cancer practice guidelines. The National Comprehensive Cancer Network. Oncology (Williston Park) 1996; 10(11 Suppl):265-288.

19. Millikan R, Logothetis C. Update of the NCCN guidelines for treatment of prostate cancer. Oncology (Williston Park) 1997;11:180-193.

20. Logothetis CJ, Millikan R. Update: NCCN practice guidelines for the treatment of prostate cancer. Oncology-New York 1999;13:118-132.

21. Bahnson RR, Hanks GE, Huben RP, et al. NCCN Practice Guidelines for Prostate Cancer. Oncology (Williston Park) 2000;14:111-119.

22. Scherr D, Swindle PW, Scardino PT. National Comprehensive Cancer Network guidelines for the management of prostate cancer. Urology 2003;61(Suppl 1):14-24.

23. Mohler J, Babaian RJ, Bahnson RR, et al. Prostate cancer. Clinical practice guidelines in oncology. J Natl Compr Canc Netw 2007;5:650-683.

24. National Comprehensive Cancer Network. Prostate cancer. NCCN Clinical Practice Guidelines in Oncology. J Natl Compr Canc Netw 2004;2:224-248. To view the most recent version of these guidelines, visit NCCN.org.

25. Mitchell JM. Urologists' self-referral for pathology of biopsy specimens linked to increased use and lower prostate cancer detection. Health Aff (Millwood) 2012;31:741-749.

26. Mitchell JM. Urologists' use of intensity-modulated radiation therapy for prostate cancer. N Engl J Med 2013;369:1629-1637 
27. Johnson CH, ed. The SEER Program Coding and Staging Manual 2004 Revision 1. National Cancer Institute, NIH Publication number 04-5581, Bethesda, MD; 2004.

28. Charlson ME, Pompei $\mathrm{P}$, Ales KL, et al. A new method of classifying prognostic comorbidity in longitudinal studies: development and validation. J Chron Dis 1987;40:373-383.

29. Quek RG, Master VA, Ward KC, et al. Determinants of the combined use of external beam radiotherapy and brachytherapy for low-risk, clinically localized prostate cancer. Cancer 2013;119:3619-3628.

30. Kind AJ, Bartels C, Mell MW, et al. For-profit hospital status and rehospitalizations at different hospitals: an analysis of Medicare data. Ann Intern Med 2010;153:718-727.

31. Department of Health and Human Services: Centers for Medical \& Medicaid Services. The Basics of Medicare Enrollment for Institutional Providers: Provider-Supplier Enrollment Fact Sheet Series. Available at: http://www.cms.gov/Outreach-and-Education/Medicare-LearningNetwork-MLN/MLNProducts/downloads/MedEnroll_InstProv FactSheet_ICN903783.pdf.

32. Littell RC, Milliken GA, Stroup WW, et al, eds. SAS for Mixed Models. 2nd ed. Cary, NC: SAS Institute Inc.; 2006.

33. Breslow NE, Clayton DG. Approximate inference in generalized linear mixed models. J Am Stat Assoc 1993;88:9-25.

34. Wolfinger R, O'connell M. Generalized linear mixed models a pseudolikelihood approach. J Stat Comput Simul 1993;48:233-243.

35. Hershman DL, Buono D, McBride RB, et al. Surgeon characteristics and receipt of adjuvant radiotherapy in women with breast cancer. J Natl Cancer Inst 2008;100:199-206.

36. Shahinian VB, Kuo YF, Freeman JL, et al. Characteristics of urologists predict the use of androgen deprivation therapy for prostate cancer. J Clin Oncol 2007;25:5359-5365.

37. Quek RG, Master VA, Portier KM, et al. Association of reimbursement policy and urologists' characteristics with the use of medical androgen deprivation therapy for clinically localized prostate cancer. Urol Oncol 2014;32:748-760.

38. Hershman DL, Buono D, McBride RB, et al. Influence of private practice setting and physician characteristics on the use of breast cancer adjuvant chemotherapy for elderly women. Cancer 2009;115:3848-3857.

39. Cooperberg MR, Broering JM, Carroll PR. Time trends and local variation in primary treatment of localized prostate cancer. J Clin Oncol 2010;28:1117-1123.

40. Fung-Kee-Fung SD, Porten SP, Meng MV, Kuettel M. The role of active surveillance in the management of prostate cancer. J Natl Compr Canc Netw 2013;11:183-187.

41. Aizer AA, Paly JJ, Zietman AL, et al. Models of care and NCCN guideline adherence in very-low-risk prostate cancer. J Natl Compr Canc Netw 2013;11:1364-1372.
42. Social Security Administration. Actuarial Life Table. Available at: http:// www.ssa.gov/OACT/STATS/table4c6.html. Accessed February 6, 2015.

43. Donovan J, Hamdy F, Neal D, et al. Prostate Testing for Cancer and Treatment (ProtecT) feasibility study. Health Technol Assess 2003;7:1-88.

44. Darves B. Physician compensation models: big changes ahead. Available at: http://www.nejmcareercenter.org/article/physician-compensationmodels-big-changes-ahead/. Accessed February 6, 2015.

45. Shen J, Andersen R, Brook R, et al. The effects of payment method on clinical decision-making: physician responses to clinical scenarios. Med Care 2004:42:297-302.

46. United States Government Accountability Office. Medicare: higher use of advanced imaging services by providers who self-refer costing Medicare millions. Available at: http://www.gao.gov/assets/650/648988.pdf. Accessed February 6, 2015

47. United States Government Accountability Office. Higher use of costly prostate cancer treatment by providers who self-refer warrants scrutiny. Available at: http://www.gao.gov/assets/660/656026.pdf. Accessed February 6, 2015.

48. Frey BS. On the relationship between intrinsic and extrinsic work motivation1. Int J Ind Organ 1997;15:427-439.

49. Loomes G, Sugden R. Regret theory: an alternative theory of rational choice under uncertainty. Econ J (London) 1982;92:805-824.

50. Kuhn M. Quality in primary care: economic approaches to analysing quality-related physician behaviour. London, Office of Health Economics; 2003.

51. Feinstein AR: The 'chagrin factor' and qualitative decision analysis. Arch Intern Med 1985;145:1257-1259.

52. Eisenberg JM. Physician utilization: the state of research about physicians' practice patterns. Med Care 1985;23:461-483.

53. Surveillance, Epidemiology, and End Results, Fast Stats, SEER-18, AgeSpecific (Crude) Incidence Rates, 2000-2009. Available at: http://www. seer.cancer.gov/faststats/. Accessed February 24, 2015.

54. The Henry J. Kaiser Foundation. Medicare Chartbook, 2010. Available at: http://kff.org/medicare/report/medicare-chartbook-2010/. Accessed February 6, 2015.

55. Diefenbach MA, Dorsey J, Uzzo RG, et al. Decision-making strategies for patients with localized prostate cancer. Semin Urol Oncol 2002;20:55-62.

56. Zeliadt SB, Moinpour CM, Blough DK, et al. Preliminary treatment considerations among men with newly diagnosed prostate cancer. Am J Manag Care 2010;16:e121-130. 
Supplemental online content for:

\section{Association Between Urologist Characteristics and Radiation Oncologist Consultation for Patients With Locoregional Prostate Cancer}

Ruben G.W. Quek, PhD; Kevin C. Ward, PhD, MPH; Viraj A. Master, MD, PhD;

Chun Chieh Lin, PhD, MBA; Kenneth M. Portier, PhD;

Katherine S. Virgo, PhD, MBA; and Joseph Lipscomb, PhD

J Natl Compr Canc Netw 2015;13:303-309

- eTable 1: Patients Consulting a Radiation Oncologist Within 9 Months After Prostate Cancer Diagnosis by an Index Urologist

- eTable 2: Unadjusted Univariate and Adjusted Multivariate Multilevel Regression Models Predicting Odds Of Consulting a Radiation Oncologist Among Patients With Locoregional Prostate Cancer

- eTable 3: Characteristics of Index Urologists Who Diagnosed Patients From 2004 to 2007 With Locoregional Prostate Cancer 


\begin{tabular}{|c|c|c|c|}
\hline & n (\%) & $\begin{array}{l}\text { Percentage of Patients } \\
\text { Consulting a Radiation } \\
\text { Oncologist }\end{array}$ & $P$ Value $^{\mathrm{a}}$ \\
\hline All patients & $39,934(100.0)$ & 61.5 & \\
\hline \multicolumn{4}{|c|}{ Patient sociodemographic characteristics } \\
\hline \multicolumn{2}{|l|}{ Age at diagnosis } & & $<.0001$ \\
\hline $66-69$ y & $10,837(27.1)$ & 57.5 & \\
\hline $70-74$ y & $12,784(32.0)$ & 68.8 & \\
\hline $75-79$ y & $9553(23.9)$ & 68.6 & \\
\hline $80-84$ y & $4891(12.2)$ & 50.4 & \\
\hline$\geq 85$ y & $1869(4.7)$ & 26.9 & \\
\hline \multicolumn{2}{|l|}{ Race/ethnicity } & & $<.0001$ \\
\hline $\begin{array}{l}\text { Non-Hispanic } \\
\text { white }\end{array}$ & $31,073(77.8)$ & 63.0 & \\
\hline $\begin{array}{l}\text { Non-Hispanic } \\
\text { black }\end{array}$ & $2916(7.3)$ & 62.3 & \\
\hline Hispanic & $2649(6.6)$ & 54.9 & \\
\hline $\begin{array}{l}\text { Non-Hispanic } \\
\text { Asian/Pacific } \\
\text { Islander }\end{array}$ & $1758(4.4)$ & 64.3 & \\
\hline Other/unknown & $1538(3.9)$ & 37.6 & \\
\hline Marital status & & & $<.0001$ \\
\hline Married & $27,344(68.5)$ & 64.4 & \\
\hline Not married & $7393(18.5)$ & 62.8 & \\
\hline Unknown & $5197(13.0)$ & 43.9 & \\
\hline \multicolumn{2}{|c|}{ SEER region of residence } & & $<.0001$ \\
\hline Georgia & $1608(4.0)$ & 65.5 & \\
\hline California & $13,452(33.7)$ & 58.1 & \\
\hline Connecticut & 2659 (6.7) & 72.6 & \\
\hline Detroit & $3421(8.6)$ & 61.8 & \\
\hline Hawaii & $721(1.8)$ & 70.7 & \\
\hline lowa & $2377(6.0)$ & 52.7 & \\
\hline Kentucky & $2919(7.3)$ & 59.9 & \\
\hline New Jersey & 7070 (17.7) & 70.6 & \\
\hline New Mexico & $961(2.4)$ & 48.8 & \\
\hline Seattle & 3085 (7.7) & 59.2 & \\
\hline Utah & $1661(4.2)$ & 50.6 & \\
\hline \multicolumn{2}{|l|}{ Rural status } & & .089 \\
\hline Nonrural & 39,265 (98.3) & 61.5 & \\
\hline Rural & $669(1.7)$ & 58.3 & \\
\hline \multicolumn{3}{|c|}{ Census tract: percentage of adults with less than a high school education } & $<.0001$ \\
\hline$<7.5$ & $10,031(25.1)$ & 63.0 & \\
\hline 7.5 to $<13.3$ & $10,010(25.1)$ & 63.0 & \\
\hline 13.3 to $<21.6$ & $9923(24.8)$ & 61.1 & \\
\hline$\geq 22.6$ & $9970(25.0)$ & 58.7 & \\
\hline \multicolumn{2}{|c|}{ Census tract: median income (\$USD) } & & $<.0001$ \\
\hline$<37,400$ & $9961(24.9)$ & 58.2 & \\
\hline 37,400 to $<50,500$ & $10,007(25.1)$ & 59.5 & \\
\hline 50,500 to $<67,700$ & $9972(25.0)$ & 63.1 & \\
\hline$\geq 67,700$ & $9994(25.0)$ & 65.2 & \\
\hline
\end{tabular}

(continued on next page)

Abbreviations: \$USD, US dollars; PSA, prostate-specific antigen.

a $P$ values calculated from 2-sided chi-squared tests for heterogeneity in proportion of patients consulting a radiation oncologist across different patient and urologists' characteristics.

${ }^{b}$ Comorbidity index based on a modification of the Charlson comorbidity index.

'Defined as the number of unique patients with prostate cancer that each urologist saw during the study period. 


\section{eTable 1 Patients Consulting a Radiation Oncologist Within 9 Months \\ After Prostate Cancer Diagnosis by an Index Urologist (cont.)}

\begin{tabular}{|lll|} 
& $\begin{array}{l}\text { Percentage of } \\
\text { Patients Consulting a } \\
\text { Radiation Oncologist }\end{array} \quad P$ Value $^{\mathrm{a}}$ \\
\hline
\end{tabular}

\section{Patient clinical characteristics}

Comorbidity index

$\begin{array}{lrr}0 & 24,856(62.2) & 61.8 \\ 1 & 9711(24.3) & 61.7 \\ 2 & 3197(8.0) & 60.3 \\ \geq 3 & 2170(5.4) & 58.8\end{array}$

Clinical tumor stage

58.8

T1

$17,153(43.0)$

$<.0001$

$\mathrm{T} 2$

20,074 (50.3)

74.8

T3

$2310(5.8)$

52.8

T4

$184(0.5)$

40.6

Unknown

$213(0.5)$

45.1

40.4

Regional lymph node metastasis stage

NO

38,937 (97.5)

61.6

N1

$306(0.8)$

45.1

NX/unknown

$691(1.7)$

59.2

Tumor grade

$235(0.6)$

$<.0001$

$\begin{array}{lc}\text { Low } & 235(0.6) \\ \text { Intermediate } & 17,230(43.1) \\ \text { High } & 21,753(54.5) \\ \text { Unknown } & 716(1.8)\end{array}$

52.8

64.0

A level at diagnosis $(\mathrm{ng} / \mathrm{mL})$

$16(1.8)$

60.1

46.6

PSA level at diagnosis $(\mathrm{ng} / \mathrm{mL})$

$$
\begin{aligned}
& 0.1-9.9 \\
& 10.0-20.0
\end{aligned}
$$

$>20.0$

Unknown

Year of diagnosis

$\begin{array}{lr}2004 & 10,268(25.7) \\ 2005 & 9606(24.1) \\ 2006 & 10,160(25.4) \\ 2007 & 9900(24.8)\end{array}$

$24,332(60.9)$
$6395(16.0)$
$3501(8.8)$
$5706(14.3)$

$10,268(25.7)$
$9606(24.1)$
$10,160(25.4)$
$9900(24.8)$

66.7

63.7

55.8

40.0

.120

62.5

60.9

(continued on next page)

Abbreviations: \$USD, US dollars; PSA, prostate-specific antigen.

${ }^{a} P$ values calculated from 2-sided chi-squared tests for heterogeneity in proportion of patients consulting a radiation oncologist across different patient and urologists' characteristics.

${ }^{b}$ Comorbidity index based on a modification of the Charlson comorbidity index.

'Defined as the number of unique patients with prostate cancer that each urologist saw during the study period. 


\begin{tabular}{|c|ccc|}
\hline eTable 1 Patients Consulting a Radiation Oncologist Within 9 Months \\
After Prostate Cancer Diagnosis by an Index Urologist (cont)
\end{tabular}

Abbreviations: \$USD, US dollars; PSA, prostate-specific antigen.

a $P$ values calculated from 2-sided chi-squared tests for heterogeneity in proportion of patients consulting a radiation oncologist across different patient and urologists' characteristics.

${ }^{b}$ Comorbidity index based on a modification of the Charlson comorbidity index.

cDefined as the number of unique patients with prostate cancer that each urologist saw during the study period. 
eTable 2 Unadjusted Univariate and Adjusted Multivariate Multilevel

Regression Models Predicting Odds Of Consulting a Radiation

Oncologist Among Patients With Locoregional Prostate Cancer

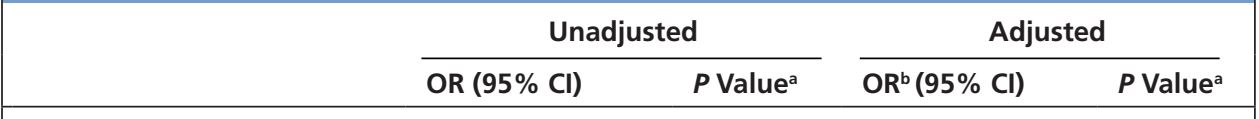

Patient sociodemographic characteristics

Age at diagnosis

$\begin{array}{lllll}66-69 \mathrm{y} & 1.00 \text { (Referent) } & & 1.00 \text { (Referent) } & \\ 70-74 \mathrm{y} & 1.68(1.58-1.79) & <.0001 & 1.62(1.52-1.72) & <.0001 \\ 75-79 \mathrm{y} & 1.62(1.50-1.75) & <.0001 & 1.57(1.45-1.70) & <.0001 \\ 80-84 \mathrm{y} & 0.68(0.62-0.75) & <.0001 & 0.69(0.62-0.76) & <.0001 \\ \geq 85 \mathrm{y} & 0.22(0.19-0.25) & <.0001 & 0.23(0.20-0.27) & <.0001\end{array}$

Race/ethnicity

Non-Hispanic white

1.00 (Referent)

1.00 (Referent)

Non-Hispanic black

0.99 (0.90-1.10)

.880

0.90 (0.80-1.00)

.050

Hispanic

$0.74(0.68-0.82)$

$<.0001$

$0.75(0.68-0.83)$

$<.0001$

Non-Hispanic Asian/

$0.90(0.78-1.04)$

.139

$0.88(0.76-1.03)$

.106

Pacific Islander

Other/unknown

$0.37(0.32-0.42) \quad<.0001$

$0.52(0.45-0.61)$

$<.0001$

Marital status

Married

1.00 (Referent)

1.00 (Referent)

Not married

$0.92(0.87-0.98)$

.006

$0.99(0.93-1.06)$

.793

Unknown

$0.38(0.35-0.42)$

$<.0001$

$0.53(0.48-0.59)$

$<.0001$

SEER region of residence

Georgia

1.00 (Referent)

1.00 (Referent)

California

0.66 (0.53-0.82)

.0002

0.78 (0.62-0.99)

.039

Connecticut

1.38 (1.07-1.77)

.012

1.43 (1.11-1.86)

.007

Detroit

$0.76(0.58-0.99)$

.043

1.31 (0.98-1.77)

.071

Hawaii

$1.22(0.81-1.82)$

.345

1.95 (1.30-2.93)

.001

lowa

$0.52(0.39-0.67)$

$<.0001$

$0.65(0.49-0.86)$

.003

Kentucky

$0.72(0.55-0.93)$

.013

0.89 (0.67-1.17)

.392

New Jersey

1.19 (0.94-1.50)

.152

1.44 (1.13-1.85)

.004

New Mexico

$0.49(0.34-0.70)$

.0001

0.74 (0.51-1.06)

.102

Seattle

0.75 (0.57-1.00)

.049

$1.06(0.79-1.44)$

.695

Utah

$0.47(0.35-0.64)$

$<.0001$

$0.59(0.43-0.81)$

.001

Rural status

Nonrural $\quad 1.00$ (Referent) 1.00 (Referent)

Rural

$0.91(0.77-1.09)$

.300

1.04 (0.87-1.26)

.652

Census tract: percentage of adults with less than a high school education

$\begin{array}{lcccc}<7.5 & 1.00 \text { (Referent) } & & 1.00 \text { (Referent) } & \\ 7.5 \text { to }<13.3 & 0.97(0.91-1.03) & .267 & 0.95(0.88-1.02) & .175 \\ 13.3 \text { to }<21.6 & 0.89(0.84-0.95) & .001 & 0.89(0.81-0.97) & .008 \\ \geq 22.6 & 0.83(0.77-0.89) & <.0001 & 0.85(0.77-0.95) & .003 \\ \begin{array}{l}\text { Census tract: median income (\$USD) } \\ \text { <37,400 }\end{array} & 1.00 \text { (Referent) } & & 1.00 \text { (Referent) } & \\ 37,400 \text { to }<50,500 & 1.09(1.02-1.16) & .009 & 1.01(0.94-1.09) & .739 \\ 50,500 \text { to }<67,700 & 1.17(1.09-1.25) & <.0001 & 0.99(0.91-1.09) & .891 \\ \geq 67,700 & 1.27(1.17-1.36) & <.0001 & 0.98(0.87-1.09) & .663\end{array}$

Abbreviations: \$USD, US dollars; OR, odds ratio; PSA, prostate-specific antigen.

(continued on next page)

a $P$ values calculated from hierarchical generalized linear mixed models.

${ }^{\mathrm{b}} \mathrm{A}$ single multivariate model, that included all the patient sociodemographic, clinical, and urologist characteristics listed in Table 2, was used to obtain the adjusted ORs.

'Comorbidity index based on a modification of the Charlson comorbidity index.

${ }^{d}$ Defined as the number of unique patients with prostate cancer that each urologist saw during the study period. 


\begin{tabular}{|c|c|c|c|c|}
\hline & \multicolumn{2}{|c|}{ Unadjusted } & \multicolumn{2}{|c|}{ Adjusted } \\
\hline & OR $(95 \% \mathrm{Cl})$ & $P$ Value $^{a}$ & $\mathrm{OR}^{\mathrm{b}}(95 \% \mathrm{Cl})$ & $P$ Value $^{\mathrm{a}}$ \\
\hline \multicolumn{5}{|c|}{ Patient clinical characteristics } \\
\hline \multicolumn{5}{|c|}{ Comorbidity index } \\
\hline 0 & 1.00 (Referent) & & 1.00 (Referent) & \\
\hline 1 & $0.99(0.94-1.04)$ & .693 & $1.01(0.95-1.06)$ & .868 \\
\hline 2 & $0.94(0.86-1.02)$ & .138 & $0.97(0.89-1.06)$ & .477 \\
\hline$\geq 3$ & $0.89(0.80-0.98)$ & .019 & $0.97(0.87-1.08)$ & .584 \\
\hline \multicolumn{5}{|c|}{ Clinical tumor stage } \\
\hline $\mathrm{T} 1$ & 1.00 (Referent) & & 1.00 (Referent) & \\
\hline $\mathrm{T} 2$ & $0.39(0.37-0.42)$ & $<.0001$ & $0.40(0.38-0.43)$ & $<.0001$ \\
\hline T3 & $0.24(0.22-0.27)$ & $<.0001$ & $0.19(0.17-0.22)$ & $<.0001$ \\
\hline T4 & $0.32(0.23-0.44)$ & $<.0001$ & $0.32(0.22-0.46)$ & $<.0001$ \\
\hline Unknown & $0.23(0.17-0.30)$ & $<.0001$ & $0.41(0.29-0.58)$ & $<.0001$ \\
\hline \multicolumn{5}{|c|}{ Regional lymph node metastasis stage } \\
\hline No & 1.00 (Referent) & & 1.00 (Referent) & \\
\hline N1 & $0.51(0.41-0.64)$ & $<.0001$ & $0.91(0.69-1.20)$ & .495 \\
\hline NX/unknown & $0.95(0.88-1.03)$ & .189 & $1.09(0.98-1.21)$ & .105 \\
\hline \multicolumn{5}{|l|}{ Tumor grade } \\
\hline Low & $0.64(0.48-0.85)$ & .0020 & $0.52(0.38-0.71)$ & $<.0001$ \\
\hline Intermediate & $1.14(1.09-1.20)$ & $<.0001$ & $0.88(0.83-0.93)$ & $<.0001$ \\
\hline High & 1.00 (Referent) & & 1.00 (Referent) & \\
\hline Unknown & $0.53(0.43-0.64)$ & $<.0001$ & $0.62(0.49-0.78)$ & $<.0001$ \\
\hline \multicolumn{5}{|c|}{ PSA level at diagnosis (ng/mL) } \\
\hline $0.1-9.9$ & 1.00 (Referent) & & 1.00 (Referent) & \\
\hline $10.0-20.0$ & $0.87(0.81-0.92)$ & $<.0001$ & $0.97(0.91-1.04)$ & .360 \\
\hline$>20.0$ & $0.60(0.55-0.66)$ & $<.0001$ & $0.78(0.71-0.85)$ & $<.0001$ \\
\hline Unknown & $0.26(0.24-0.29)$ & $<.0001$ & $0.34(0.31-0.38)$ & $<.0001$ \\
\hline \multicolumn{5}{|l|}{ Year of diagnosis } \\
\hline 2004 & 1.00 (Referent) & & 1.00 (Referent) & \\
\hline 2005 & $1.01(0.94-1.07)$ & .885 & $0.98(0.91-1.05)$ & .521 \\
\hline 2006 & $1.07(1.00-1.14)$ & .049 & $1.05(0.98-1.12)$ & .195 \\
\hline 2007 & $0.99(0.92-1.06)$ & .785 & $0.96(0.89-1.03)$ & .240 \\
\hline
\end{tabular}

(continued on next page)

Abbreviations: \$USD, US dollars; OR, odds ratio; PSA, prostate-specific antigen.

a $P$ values calculated from hierarchical generalized linear mixed models.

${ }^{\mathrm{b}} \mathrm{A}$ single multivariate model, that included all the patient sociodemographic, clinical, and urologist characteristics listed in Table 2, was used to obtain the adjusted ORs.

'Comorbidity index based on a modification of the Charlson comorbidity index.

${ }^{\mathrm{d}}$ Defined as the number of unique patients with prostate cancer that each urologist saw during the study period. 


\begin{tabular}{|c|c|c|c|c|}
\hline & \multicolumn{2}{|c|}{ Unadjusted } & \multicolumn{2}{|c|}{ Adjusted } \\
\hline & OR $(95 \% \mathrm{Cl})$ & $P$ Value ${ }^{a}$ & $\mathrm{OR}^{\mathrm{b}}(95 \% \mathrm{Cl})$ & $P$ Value $^{a}$ \\
\hline \multicolumn{5}{|l|}{ Urologist characteristics } \\
\hline \multicolumn{5}{|l|}{ Sex } \\
\hline Male & 1.00 (Referent) & & 1.00 (Referent) & \\
\hline Female & $1.14(0.90-1.46)$ & .190 & $1.22(0.92-1.62)$ & .159 \\
\hline \multicolumn{5}{|l|}{ Board certification } \\
\hline Yes & 1.00 (Referent) & & 1.00 (Referent) & \\
\hline No & $0.87(0.72-1.06)$ & .168 & $0.86(0.66-1.11)$ & .242 \\
\hline \multicolumn{5}{|l|}{ US-trained } \\
\hline Yes & 1.00 (Referent) & & 1.00 (Referent) & \\
\hline No & $0.88(0.77-1.01)$ & .061 & $0.91(0.79-1.06)$ & .235 \\
\hline \multicolumn{5}{|l|}{ Degree type } \\
\hline MD & 1.00 (Referent) & & 1.00 (Referent) & \\
\hline DO & $1.05(0.82-1.36)$ & .698 & $1.27(0.87-1.87)$ & .213 \\
\hline \multicolumn{5}{|l|}{ Age } \\
\hline$<43 y$ & 1.00 (Referent) & & 1.00 (Referent) & \\
\hline $43-50 y$ & $1.10(0.97-1.25)$ & .140 & $1.10(0.97-1.26)$ & .129 \\
\hline $51-57$ y & $0.93(0.82-1.06)$ & .292 & $1.04(0.90-1.19)$ & .615 \\
\hline$>57$ y & $1.08(0.96-1.22)$ & .224 & $1.21(1.07-1.38)$ & .003 \\
\hline \multicolumn{5}{|l|}{ Patient volume $^{\mathrm{d}}$} \\
\hline$<37$ & 1.00 (Referent) & & 1.00 (Referent) & \\
\hline $37-54$ & $0.92(0.82-1.04)$ & .171 & $0.88(0.78-1.00)$ & .049 \\
\hline $55-77$ & $0.90(0.79-1.03)$ & .116 & $0.89(0.77-1.01)$ & .079 \\
\hline$>77$ & $0.91(0.79-1.04)$ & .177 & $0.95(0.82-1.09)$ & .444 \\
\hline \multicolumn{5}{|c|}{ Medical School Affiliation } \\
\hline Major & 1.00 (Referent) & & 1.00 (Referent) & \\
\hline Mixed & $1.12(0.86-1.46)$ & .417 & $1.08(0.82-1.42)$ & .579 \\
\hline None & $0.93(0.75-1.16)$ & .532 & $1.06(0.84-1.33)$ & .651 \\
\hline Noninstitutional & $1.21(1.02-1.43)$ & .030 & $1.40(1.17-1.67)$ & .0002 \\
\hline
\end{tabular}

Abbreviations: \$USD, US dollars; OR, odds ratio; PSA, prostate-specific antigen.

a $P$ values calculated from hierarchical generalized linear mixed models.

bA single multivariate model, that included all the patient sociodemographic, clinical, and urologist characteristics listed in Table 2, was used to obtain the adjusted ORs.

'Comorbidity index based on a modification of the Charlson comorbidity index.

${ }^{d}$ Defined as the number of unique patients with prostate cancer that each urologist saw during the study period. 


\begin{tabular}{|c|c|c|}
\hline \multicolumn{3}{|c|}{$\begin{array}{c}\text { eTable } 3 \text { Characteristics of Index Urologists Who } \\
\text { Diagnosed Patients From } 2004 \text { to } 2007 \\
\text { With Locoregional Prostate Cancer }\end{array}$} \\
\hline & $\mathbf{n}$ & $\%$ \\
\hline All urologists & 2405 & \\
\hline \multicolumn{3}{|l|}{ Age } \\
\hline$<43 y$ & 728 & 30.3 \\
\hline $43-50 y$ & 561 & 23.3 \\
\hline $51-57$ y & 488 & 20.3 \\
\hline$>57$ y & 628 & 26.1 \\
\hline \multicolumn{3}{|l|}{ Sex } \\
\hline Male & 2329 & 96.8 \\
\hline Female & 76 & 3.2 \\
\hline \multicolumn{3}{|l|}{ Board certification } \\
\hline Yes & 2247 & 93.4 \\
\hline No & 158 & 6.6 \\
\hline \multicolumn{3}{|l|}{ US-trained } \\
\hline Yes & 2030 & 84.4 \\
\hline No & 375 & 15.6 \\
\hline \multicolumn{3}{|l|}{ Degree type } \\
\hline MD & 2346 & 97.6 \\
\hline DO & 59 & 2.5 \\
\hline \multicolumn{3}{|c|}{ Years after medical school graduation } \\
\hline$<16$ & 722 & 30.0 \\
\hline $16-23$ & 523 & 21.8 \\
\hline $24-31$ & 525 & 21.8 \\
\hline$>31$ & 635 & 26.4 \\
\hline \multicolumn{3}{|l|}{ Patient volume ${ }^{a}$} \\
\hline$<37$ & 1455 & 60.5 \\
\hline $37-54$ & 423 & 17.6 \\
\hline $55-77$ & 312 & 13.0 \\
\hline$>77$ & 215 & 8.9 \\
\hline \multicolumn{3}{|l|}{ Medical school affiliation } \\
\hline Major & 153 & 6.4 \\
\hline Mixed & 76 & 3.2 \\
\hline None & 136 & 5.7 \\
\hline Noninstitutional & 2040 & 84.8 \\
\hline
\end{tabular}

aDefined as the number of unique patients with prostate cancer that each urologist saw during the study period. 